\title{
Acoustic Interference on a Visual Attention Task in Relation to the Perceptual Load
}

\author{
Jesus M Alvarado*, Carmen Santisteban and Manuel Cortijo
}

Complutense University of Madrid, Spain

Received: December 22, 2013; Accepted: February 14, 2014; Published: February 19, 2014

*Corresponding author: Jesus M Alvarado, Department of Methodology of Behavioural Sciences, Faculty of Psychology, Complutense University of Madrid, Campus de Somosaguas, 28223 Madrid, Spain, E-mail: alvarado@psi.ucm.es

\begin{abstract}
We have studied the interference of irrelevant information on the visual selective attention and whether load effects are modality specific or can be obtained across the visual and auditory modalities. The interference of irrelevant stimuli in the selective attention on a flanker task was measured by the flanker effect also called response compatibility effect (RCE). The influence of a 100 Hertz tone (60 $\mathrm{dAB}$ ) on the flanker task was evaluated in three experiments. It was observed that subjects carried out the flanker task faster and more accurately in the presence than in the absence of these sounds at the two target-distractors (T-D) distances $\left(0.65^{\circ}\right.$ and $\left.1.30^{\circ}\right)$ and three display sizes (with 3, 5 and 9 elements) assayed. It was also observed an acoustic Simon effect that interfered the visual processing, significantly increasing the RCE with respect to when the stimulus was congruent (coming from the same side). A crossmodal effect was observed in cases of low perceptual load, that is, when few elements are presented on the screen and the flanker are located far from the target.
\end{abstract}

\section{Introduction}

The selective or focused attention to a particular stimulus implies that the subject ought to ignore each other stimuli. The grade as to which irrelevant stimuli can be successfully ignored has been a topic of permanent controversy in experimental psychology during last 40 years. Experimental evidences have led to several attentional models, which suggest that attention acts like an adjustable focus to relevant stimuli, (e.g. zoom-lens model by Eriksen and St. James [1] and gradient model by LaBerge and Brown [2]. Further insight into the attentional process might come from the study of the influence of the perceptual load and whether or no the visual focus is specific to visual stimuli as was pointed out by Cowan et al. [3] saying that "the focus covers all modalities and codes" (page 50).

Lavie et al. [4-8] have proposed that the extent to which irrelevant distractors can be excluded from perception depends on the level of perceptual load present while processing relevant stimuli. Situations of high perceptual load in relevant processing will exhaust perceptual capacity, leaving none of this capacity available for processing distractors, and so inevitably excluding them from perception. There are many evidences about the limited processing capacity for stimuli presented within the same sensory modality and a relevant question to study is whether similar limitations appear when the stimuli are presented across different modalities. This topic is also relevant to many recent studies on working memory and on the control of attention, including the ability to avoid distraction by irrelevant stimuli [9-13]. That is, a relevant open question is whether the attentional control is or not supramodal in nature [14-24]. The first aim of this paper was to contribute to the understanding of this important open question. Hence, we have carried out experiments using a visual attentional task in the absence and in the presence of irrelevant stimuli of a different modality (acoustic). A second aim of this work was to examine the question of whether irrelevant non-visual stimuli are or not ignored in terms of the visual perceptual load, which might also help to a better comprehension of the attentional control. Hence, we have also studied the influence of the visual load in the absence and presence of the acoustic stimuli.

We have chosen the flanker task Eriksen and Eriksen [25], to carry out our attentional experiments. This task has often been used to measure the effect of irrelevant visual stimuli on the relevant task and the influence of many experimental conditions on the subject's responses has been adequately characterized [26-28]. Changes in the perceptual visual load, the addition of other stimuli of the same modality, the addition of cues, etc., may be done in this task by an easy and well-known way. Moreover, the effects of all these manipulations using exclusively visual stimuli have been already studied in depth and they may aid to elucidate the effects produced by the addition of non-visual stimuli to the visual task. In the classical flanker task, there is one central target surrounded by distractors and subjects are instructed to ignore the distractors (flankers) and to respond to the target. Many previous results have shown that when the display included incompatible distractors (those assigned to a response different from the response assigned to the target) the response times (RTs) were longer than when the distractors were compatible (those assigned to the same response as the target). The difference between the RTs in both 
conditions is a measure of the distractor interference and is known as flanker interference or response-compatibility effect (RCE). The most important paradigm finding is that the RCE decreases as the target-distractors distance increases [1,28,29], which was explained in the context of the CTVA model by a better discrimination between target and distractor perceptions when the visual focus increased $[26,30,31]$ In the present study we have added an irrelevant acoustic stimulus to the visual flanker task. The sound, emitted in a free field, came from a loudspeaker to the right or left of the subject or from both sides at the same time. Three types of trials were considered taking into account the side of the sound came from. They were: (a) congruent trials (also called spatially congruent) when the acoustic stimulus came from the same side to the response demanded (e.g., left response and acoustic stimulus coming from the left side); (b) incongruent trials when the sound came from the opposite side to the response demanded; and (c) neutral trials when the sound came from both sides.

The effects of the attentional focus size $\left(0.65^{\circ}\right.$ and $\left.1.30^{\circ}\right)$ and number of items displayed (3, 5 and 9) on the RTs and accuracy of the responses were studied in a first experiment using exclusively visual stimuli. This experiment was planned as a test with respect to previous studies carried out in similar conditions $[26,27]$ and as a control for all our further experiments. The effect of an acoustic stimulus (irrelevant task) on a selective visual attention task was studied in a second experiment, carried out under the same conditions than in the first experiment. Crossmodal Simon effects have been studied with many paradigms from a long time ago $[32,33]$. Nevertheless we presented the acoustic stimuli $100 \mathrm{~ms}$ earlier than the visual stimuli and the former may be considered as previous non-informative cues. The influence of informative and non-informative acoustic cues on visual tasks has been previously studied by many other authors, which allowed a better understanding of these cross-modal links [34-38]. At any case, and according to previous studies, we hoped to obtain a facilitation effect of the acoustic stimuli (with regard to the silence condition) on the RT and accuracy of the visual task. Our intention carrying out this second experiment was however more ambitious, because we hypothesize that, under a low perceptual load, a different cross-modal effect for each type of acoustic stimulus should be observed. That is, the congruent trials (same side) would have faster RTs, lower amount of incorrect responses and shorter flanker-interferences (RCE) than the incongruent (opposite side) trials, at least under low perceptual load conditions. The results obtained in the second experiment appeared to support our hypothesis on the existence of crossmodal interference on the selective attention at certain conditions, but the complexity of paradigm used and the large number of variables studied made the agreement arguable. Hence, a third experiment was designed to overcome the controversial points and the hypothesis was again confirmed.

\section{Experiment 1}

\section{Method}

Subjects: The participants were 12 doctoral students (8 females) between 23 and 30 years old from the Complutense
University of Madrid (Spain). All the subjects were right-handed and had normal or corrected-to-normal vision.

Apparatus and stimuli: A standard personal computer was used to present the visual stimuli and to collect the subjects' responses. Stimuli presentation and response recording were controlled by a C++ program designed "ad hoc" for this experiment as a version of the program DEVAT [39]. The subjects gave their responses through the computer keyboard.

The subject's task was to identify a target letter among distractors. The target appeared in the center of the computer screen surrounded by two, four or eight distractors (see Figure 1). The experiments were carried out in two separate sessions: In the first session the subject was asked to press the left-arrow key $(\leftarrow)$ of the keyboard with the index finger of the right hand if the target letter was "q" or "d", and to press the right-arrow key $(\rightarrow)$ with the middle finger of the same right hand if the target letter was "p" or " $b$ ". In the second session the subject was asked to carry out the task using the both hands, pressing the $\mathbf{Q}$ key with the middle finger of left hand if the target letter was "q" or " $\mathrm{d}$ " or pressing the $\mathbf{P}$ key with the middle finger of the right hand if it was "p" or "b".

In both sessions these four target letters appeared at random with equal probability. Distracting letters were also presented at random. The target and distractors appeared simultaneously. All the letters were white lower case (luminance: $116 \mathrm{~cd} / \mathrm{m}^{2}$ ) presented on a black background (luminance: $1 \mathrm{~cd} / \mathrm{m}^{2}$ ). Each letter subtended a $0.40^{\circ}$ visual angle.

Three independent variables were considered: the compatibility of the target and the distractors, the display size, and the distance between the target and each distractor. Compatibility had three levels: (i) compatible response condition, where the distractors belonged to the same type of response as the target letter (i.e. if the target was "b" or " $p$ " the distractors had also to be either " $b$ " or " $p$ "); (ii) incompatible response condition, where the distractors were associated with the opposite target type (i.e. if the target was "b" or "p" the distractors had to be either "d" or "q"); and (iii) neutral condition, where the distractors were either " $\mathrm{z}$ " or " $\mathrm{x}$ ". The display sizes were 3, 5 and 9, as indicated above (Figure 1). The targetdistractor (T-D) distances were $0.65^{\circ}$ and $1.30^{\circ}$, all distances being taken from the centre of the letters.

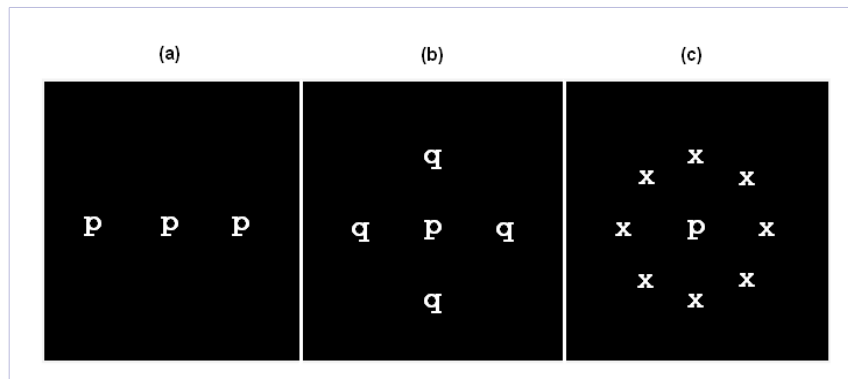

Figure 1: Three examples of the display sizes and trial types utilized: (a) compatible (b) incompatible, and (c) neutral for a target demanding a right response. 
Design: A factorial design of repeated measurements was used. Eighteen display types were obtained by combining all modalities of the three independent variables; that is, compatibility of the distractors (3) x display size (3) x T-D distance (2). Each of the $18(3 \times 3 \times 2)$ displays was presented 30 times in each of two counterbalanced sessions (a total of $18 \times 30 \times$ $2=1080$ trials each subject), in the first session responding with the right hand alone and in the second one using both hands as has been described above. The order of presentation of the 1080 trials was randomized. The dependent variables considered were the RTs and accuracy (percentage of incorrect responses), these being recorded for each trial in a computer file.

Procedure: The subjects performed the task in a soundproof room resting their heads on a chin-rest. Illumination and other environmental conditions were kept constant. The viewing distance was $90 \mathrm{~cm}$, equal than used in previous works [4041]. Each trial began with a fixation point (+) for $1000 \mathrm{~ms}$ in the centre of the computer screen (at the same point at which the target letter will later appear). Then, the target and distractors appeared simultaneously on a display, which remained on the screen until the subject responded. The subjects were instructed to keep their eyes on the fixation point and to respond only to the target letter, as quickly as possible while avoiding errors. The subject had to push the space bar to start the next trial. Visual feedback for incorrect responses was provided. The subjects started with a pilot session consisting of 50 trials randomly selected from the different 18 displays considered. Responses from this pilot session were not used in data analysis. Only RT's smaller than $1000 \mathrm{~ms}$ and errorless trials were included in the RT analyses. Thus 201 out of 12960 trials (1.55 \%) were discarded.

\section{Results}

A within-subject repeated-measure ANOVA was made for RT's, taking into account the following factors: (i) T-D distance; (ii) compatibility of distractors; (iii) display size; and (iv) session (one or both hands). There were significant main effects of T-D distance $\mathrm{F}(1,11)=107.82, \mathrm{MSE}=39083, \mathrm{p}<0.001(\mathrm{M}=452 \mathrm{~ms}$ for $0.65^{\circ}$ and $\mathrm{M}=433 \mathrm{~ms}$ for $\left.1.30^{\circ}\right)$ and compatibility $\mathrm{F}(2,22)=$ 60.75, MSE $=33021, \mathrm{p}<0.001(\mathrm{M}=433 \mathrm{~ms}$ for compatible trials, $\mathrm{M}=435 \mathrm{~ms}$ for neutral trials and $\mathrm{M}=460 \mathrm{~ms}$ for incompatible trials). No significant main effects of the display-size, $F(2,22)=$ 1.06, MSE $=209$ ) or session, $\mathrm{F}(1,11)=0.03$, MSE $=322$ ) were found. The only significant interaction was T-D distance $\mathrm{x}$ compatibility $F(2,22)=9.93, \mathrm{MSE}=4738, \mathrm{p}=0.001$ (Table 1). The post hoc analysis (Bonferroni test) showed significant differences between the two pairs: incompatible trials vs neutral trials $(\mathrm{p}<0.001)$ and incompatible trials vs compatible trials $(\mathrm{p}<$ 0.001). The difference between the compatible and neutral trials was not significant $(\mathrm{p}=1.0)$. The RCE decreased with increasing T-D distances, as was expected for an Eriksen's paradigm (Figure 2).

A within-subject repeated-measure ANOVA was made to analyze the incorrect responses variable. We only found a significant main effect of the variable compatibility $\mathrm{F}(2,22)=$ 9.25, $\mathrm{MSE}=13.19, \mathrm{p}=0.001(\mathrm{M}=0.43$ for compatible trials, $\mathrm{M}=$

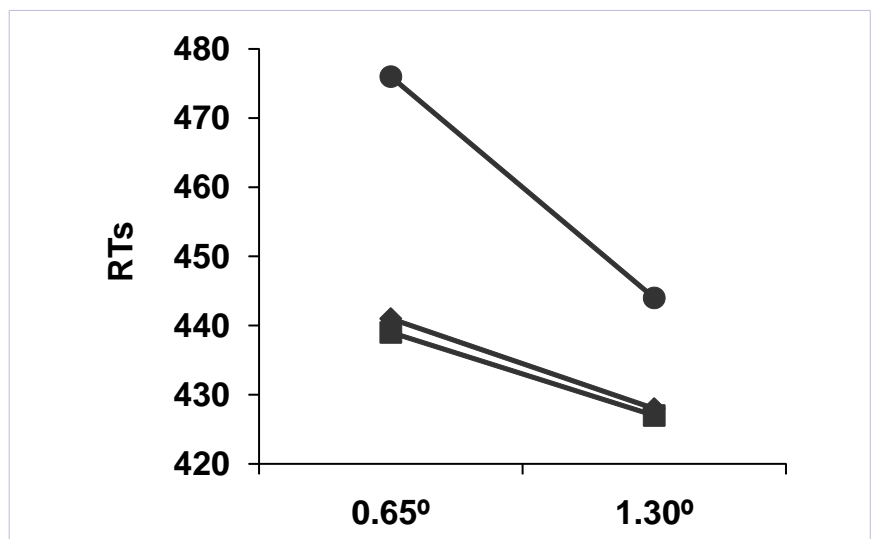

Figure 2: RTs as a function of the T-D distance and compatibility obtained in the experiment 1 ( incompatible compatible and $\bullet$ neutral).

0.55 for neutral trials and $\mathrm{M}=1.35$ for incompatible trials). The post hoc analysis (Bonferroni test) showed significant differences between the two pairs: incompatible trials vs neutral trials (p $=0.038)$ and incompatible trials vs compatible trials $(p=0.026)$. The difference between the compatible and neutral trials was not significant ( $\mathrm{p}=0.53)$.

The analyses revealed no significant differences between compatible and neutral trials in the two variables tested, RTs and percentages of incorrect responses. Hence, we have removed from this paper any further mention to the visual-neutral trials (although their analyses were carried out). The results shown in Table 1 and Figure 2 indicate that there was a significant interference-flanker effect at the two T-D distances studied, being larger at $0.65^{\circ}$ than at $1.30^{\circ}$ (RCE means equal to $37 \mathrm{~ms}$ and $17 \mathrm{~ms}$, respectively) and these results agree with many previous studies (see e.g. [26-27]).

\section{Experiment 2}

\section{Method}

Subjects, apparatus and stimuli: They were the same than in the first experiment, except the following: The personal computer that was used to present the visual stimuli and to collect the subjects' responses was equipped with an AW32 sound card, a Harman/Kardon amplifier (model HK6150) and two high fidelity RDF acoustic speakers (serie Mitto II). Sound levels were measured using a Brüel \& Kjaer sonic meter (model: 2236). The position of the speakers with respect to the subject and the computer screen is schematically represented in Figure 3.

The subject's task was identical than in the first experiment. The program also controlled the emission of the acoustic stimuli from the speakers located to the right and left of the subject. The acoustic stimuli were a 100 hertz tone presented at an intensity of $60 \mathrm{dBA}$, measured at the point where the subject was seated. Three types of trials regarding to the acoustic stimulus presentation were considered: (a) congruent or same side, (b) incongruent or opposite side, and (c) neutral or both sides. The 
sound presentation was emitted at random $100 \mathrm{~ms}$ previous to the visual stimuli appearance on the computer screen and disappeared simultaneously with the visual stimuli.

Design and procedure: A factorial design of repeated measurements was also used. Fifty and four different displays were obtained by combining all modalities of the four independent variables. That is, compatibility of the visual distractors (3) x acoustic stimulus congruency (3) x display size (3) x T-D distance (2). Each of the 54 displays was presented 20 times to each subject in two counterbalanced sessions (a total of 1080 trials each subject), in the first session responding with the right hand alone and in the second one using both hands as has been described above for the experiment 1 . The order of presentation of the 1080 trials was randomized. Each trial began with a fixation point $(+)$ for $1000 \mathrm{~ms}$ in the centre of the computer screen (at the same point at which the target letter will later appear). Then, the acoustic stimulus was brought in and the visual presentation appeared $100 \mathrm{~ms}$ later. This display and the sound remained on the screen until the subject responded.

\section{Results}

The RTs and response accuracies were smaller than those previously obtained in the absence of sounds for equal conditions (Table 1). Mean RT's and incorrect responses were separately analyzed for the two T-D distances considered. A within-subject repeated-measure ANOVA was made, taking into account the following factors: (i) compatibility of distractors; (ii) congruency of the acoustic stimulus; (iii) display size; and (iv) experimental session. Only RT's smaller than $1000 \mathrm{~ms}$ and errorless trials were included in the RT analyses. Thus 397 out of 12960 trials (3.06\%) were discarded.

Results for the $0.65^{\circ} \mathrm{T}-\mathrm{D}$ distance: There was a significant

Table 1: RTs (in ms) and percentages of incorrect responses (SD in brackets) in silence (experiment 1) and in the presence of acoustic stimuli (experiment 2).

\begin{tabular}{|c|c|c|c|c|c|}
\hline Compatibility & & \multicolumn{2}{|c|}{ Experiment 1 } & \multicolumn{2}{c|}{ Experiment 2 } \\
\hline & & $0.65^{\circ}$ & $1.30^{\circ}$ & $0.65^{\circ}$ & $1.30^{\circ}$ \\
\hline \multirow{2}{*}{ Incompatible } & RTs & $476(56)$ & $444(59)$ & $449(64)$ & $417(59)$ \\
\cline { 2 - 6 } & Errors & $1.65(2.10)$ & $1.07(1.77)$ & $3.15(4.80)$ & $1.45(2.85)$ \\
\hline \multirow{2}{*}{ Compatible } & RTs & $439(71)$ & $427(60)$ & $408(67)$ & $399(56)$ \\
\cline { 2 - 6 } & Errors & $0.37(0.72)$ & $0.48(0.97)$ & $0.60(1.55)$ & $0.65(1.35)$ \\
\hline $\mathrm{RT}_{\text {Inc }}-\mathrm{RT}_{\text {Comp }}$ & RCE & 37 & 17 & 41 & 18 \\
\hline
\end{tabular}

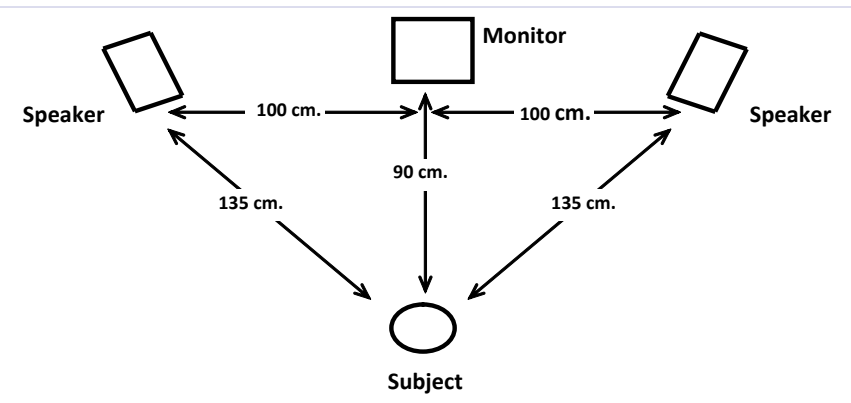

Figure 3: Relative location of the speakers, subject and monitor. main effect of compatibility $\mathrm{F}(1,11)=88.36, \mathrm{MSE}=179341$, $\mathrm{p}<.001$ (Table 1). No significant main effect of the acoustic stimulus congruency $(\mathrm{F}(2,22)=3.58$, MSE $=3591)$, the displaysize $(F(2,22)=0.43$, MSE $=133)$, and the experimental session $(F(1,11)=0.02, \operatorname{MSE}=333)$ were found.

The interaction compatibility $\mathrm{x}$ display-size $\mathrm{F}(2,22)=5.00$, MSE $=3523$, was significant $(p=0.016)$. The RT means for compatible trials decreased with the display size, being 414, 405 and $405 \mathrm{~ms}$ respectively for tree, five and nine elements displayed. On the contrary, the RT means for incompatible trials were 444 $\mathrm{ms}, 448 \mathrm{~ms}$ and $454 \mathrm{~ms}$ for these display sizes. This indicates that the flanker's interference increases with the display size, being the RCE values 30, 43 and 49 respectively for displays of three, five and nine elements.

Results for the $1.30^{\circ}$ T-D distance: Significant main effects of the compatibility $F(1,11)=37.57$, MSE $=36520, p<.001$ (Table 1), and the acoustic stimulus congruency $\mathrm{F}(2,22)=15.82$, MSE $=7969, \mathrm{p}<.01$, were observed. The effects of the displaysize $(F(2,22)=3.40$, MSE $=1401)$ and the experimental session $(F(1,11)=0.01, M S E=100)$ were not significant. Regarding to the effect of the acoustic stimulus congruency, the RT means for same side, both sides and opposite sides were 400, 409 and 415 $\mathrm{ms}$, respectively. The post hoc analysis (Bonferroni test) showed significant differences between the pairs: same side vs opposite side $(\mathrm{p}<.01)$, both sides vs same side $(\mathrm{p}=.03)$, and both sides $v s$ opposite side $(p=.048)$. Significant interactions of the acoustic stimulus congruency $\mathrm{x}$ display size $\mathrm{F}(4,44)=5.50, \mathrm{MSE}=2469$, $\mathrm{p}=.01$ and of the acoustic stimulus congruency $\mathrm{x}$ display size $\mathrm{x}$ compatibility $\mathrm{F}(4,44)=8.23$, MSE $=3924, \mathrm{p}<.01$ were found (Table 2).

Incorrect responses analysis: A within-subject repeatedmeasure ANOVA was made to analyze the incorrect responses variable. We found significant main effect of the variable compatibility in both distances. For the $0.65^{\circ} \mathrm{T}-\mathrm{D}$ distance $\mathrm{F}(1$, 11) $=8.28, \mathrm{MSE}=28.01, \mathrm{p}=.015$ and for the $1.30^{\circ} \mathrm{T}-\mathrm{D}$ distance $\mathrm{F}$ $(1,11)=10.85$, MSE $=2.68, p=.007$ (Table 1 ). The interaction of acoustic stimulus congruency $\mathrm{x}$ display size $\mathrm{F}(4,44)=4.63$, MSE $=0.63, \mathrm{p}=.003$ was significant for the $1.30^{\circ} \mathrm{T}-\mathrm{D}$ distance.

\section{Discussion}

We show in Table 1 that there was a significant interferenceflanker effect at the two T-D distances studied in the presence of sounds, being larger at $0.65^{\circ}$ than at $1.30^{\circ}$ (RCE means equal to $41 \mathrm{~ms}$ and $18 \mathrm{~ms}$, respectively), as was predicted for the flanker task by the CTVA-2D model $[27,30]$. In addition, subjects carried out the visual task faster and more accurate in the presence than in the absence of sounds at each experimental condition. It has been shown in various studies [42-47] that subjects carried out the main task better working in the presence of moderate intensity noise levels than when they did it in silence. The interpretation of this result has been that noise influences performance by causing subjects to focus their attention on those aspects of the task defined as relevant. Warner and Heimstra [48] observed that the focusing effect appears as the display size increases and similar results have been obtained with the global/ 
Table 2: RT means (SD in brackets) measured in the experiment 2 at a T-D distance of $1.30^{\circ}$, as a function of the display size, the acoustic stimulus congruency and compatibility.

\begin{tabular}{|c|c|c|c|}
\hline \multirow{4}{*}{ Display } & size \\
\hline & Tree & Five & Nine \\
\hline Compatible & $406(61)$ & $389(59)$ & $386(48)$ \\
\hline Incompatible & $405(56)$ & $405(58)$ & $412(61)$ \\
\hline RCE & -1 & 16 & 26 \\
\hline & & Both sides & \\
\hline Compatible & $396(55)$ & $397(51)$ & $400(53)$ \\
\hline Incompatible & $410(49)$ & $418(53)$ & $430(61)$ \\
\hline RCE & 14 & 21 & 30 \\
\hline & & \multicolumn{2}{|c|}{ Opposite side } \\
\hline Compatible & $403(55)$ & $407(52)$ & $406(50)$ \\
\hline Incompatible & $447(74)$ & $413(50)$ & $415(46)$ \\
\hline RCE & 44 & 6 & 9 \\
\hline
\end{tabular}

local paradigm [49,50], or with the Stroop test [51-53]. Usai and Umiltà [54] have observed that the presence of noise may bring about a change in the shape and size of attentional focus $[41,55]$. We think that similar reasons should be adduced to explain the facilitation effect observed here by the addition of acoustic stimuli to the visual flanker task.

The congruency of the acoustic stimulus had not any effect on both the RTs and the number of incorrect responses at a T-D distance of $0.65^{\circ}$, but it had a significant main effect at a T-D distance of $1.30^{\circ}$, where the visual-distractors interference (RCE) was significant smaller. At this latter distance the RTs significantly increased when the acoustic stimuli came from the same side, from both sides and from the opposite side than the response demanded (400, 409 and $415 \mathrm{~ms}$, respectively). These are the expected results for a Simon effect, although is interesting to note that it was not observed at the smaller distance used $\left(0.65^{\circ}\right)$. The acoustic stimuli were presented 100 $\mathrm{ms}$ earlier than the visual stimuli and we cannot be sure whether these changes were effectively due to a decrease of the visual focus as a consequence of a cross-modal effect or to the fact that these stimuli were non-informative cues or more probably to both reasons. This question was solved in the third experiment presenting all stimuli simultaneously.

The effect of the display size on the RTs for the compatible and incompatible conditions in the presence of acoustic stimuli (Table 2) deserves a comment, which may also explain the interactions found in the ANOVA. The RT increments with the display-size were small and in the direction predicted by the CTVA-2D model at all conditions, except for incompatible visual displays at the lower display size (3) and the highest T-D distance $\left(1.30^{\circ}\right)$, i.e., at the lowest perceptual load assayed. This high RT value measured ( $447 \mathrm{~ms}$ ) is also responsible of the high RCE (44 ms) calculated at this condition and it suggests the existence of some kind of unspecific gradient model for the cross-modal interaction, such as the proposed by Cowan $[3,56]$. In other words stimuli from different sensorial modalities may affect the visual processing by an enlargement of the focus and a reduction in resolution when the number of element displayed is small (three elements at the T-D distance of $1.30^{\circ}$ in our case). Nevertheless, the evidence supporting this explanation is meagre and it has only been obtained by comparison between two 3-way interactions. We have excluded that this value could be due to data manipulation errors, but the limited number of trials fulfilling this condition (240 trials) does not exclude that a possible artefact might also explain this discrepant point. Hence, we have again studied the influence of the acoustic stimuli on the flanker task in a third simpler experiment using less experimental conditions: an unique display size, only two visual trials (no neutrals) and only two acoustic stimuli (same and opposite side, but not both sides). It has been shown that behavioral effects in some Stroop tasks were smaller or even disappear on using long inter-trial periods [57-59]. It has also been argued that the engagement of cognitive control may be less likely to occur if there is a long delay period before control is needed [60]. Thus, we have not allowed to the subjects to choose themselves each inter-trial period, as happened in the two first experiments, and we have now started each trial every two seconds, which in addition allowed to do a greater number of assays in the same period of time. The number of subjects was also significantly increased (25 instead of 12), with the consequence that each trial type was now presented 2000 times ( $80 \times 25$ subjects) instead of $240(20 \times 12)$ in the previous experiment 2 , increasing the statistical power of the experiment. Finally all stimuli were simultaneously presented for the reasons given above.

\section{Experiment 3}

\section{Method}

Subjects: The participants were 25 students ( 15 females and 10 males) between 20 and 34, years old from the Complutense University of Madrid (Spain). All the subjects were right-handed and had normal or corrected-to-normal vision.

Apparatus, stimuli and procedure: This experiment was carried out under similar conditions to those described for the experiment 2 except by the following: (i) only the displays size = 3 with compatible (only ppp or qqq) and incompatible (only pqp or qpq) trials were used; (ii) congruent and incongruent acoustic stimuli, but not neutral, acoustic stimuli were presented; and (iii) the acoustic stimuli and visual displays were presented simultaneously. Each trial automatically started every two seconds (one spent with the fixation cross and the other presenting all stimuli). The subjects carried out the task in two separate sessions of 640 trials each. The T-D distance was $0.65^{\circ}$ in one session and $1.30^{\circ}$ in the other session. Subjects always responded using only one hand as is described above.

\section{Results}

ANOVAs were used to detect the effects of the variables acoustic stimuli congruency (same side or opposite side) and compatibility of the visual trial (compatible or incompatible). Only RT's smaller than $1000 \mathrm{~ms}$ and errorless trials were 
included in the RT analyses. Thus 2119 out of 32000 trials (6.62 $\%)$ were discarded.

Results for the $0.65^{\circ} \mathrm{T}-\mathrm{D}$ distance: A significant main effect of compatibility was observed $F(1,24)=66.79$, MSE $=130319, p$ $<0.001$ (means equal to $502 \mathrm{~ms}$ and $553 \mathrm{~ms}$ for the compatible and incompatible trials). The effect of the acoustic stimulus congruency was not significant $F(1,24)=0.82$, MSE $=473, \mathrm{p}=$ 0.38 . No significant interaction was found.

Results for the $1.30^{\circ}$ T-D distance: A main effect of the two factors studied was found: compatibility $\mathrm{F}(1,24)=17.35$, MSE $=12299, \mathrm{p}<0.001$ (means equal to $522 \mathrm{~ms}$ and $538 \mathrm{~ms}$ for the compatible and incompatible trials) and acoustic stimulus congruency $\mathrm{F}(1,24)=5.19, \mathrm{MSE}=3520, \mathrm{p}=0.03$ (means equal to $525 \mathrm{~ms}$ and $534 \mathrm{~ms}$ for congruent and incongruent trials). The interaction acoustic stimulus congruency $\mathrm{x}$ compatibility was significant $F(1,24)=13.34$, MSE $=5092, p=0.001$ as happened in the experiment 2. This effect is seen in Figure 4 where a larger RCE for the opposite side than for the same side of the acoustic conditions was observed.

Analysis of incorrect responses: Analyses of the no correct responses at $\mathrm{T}-\mathrm{D}=0.65^{\circ}$ showed a main effect of the compatibility $\mathrm{F}(1,24)=38.79, \mathrm{MSE}=1601, \mathrm{p}<.001$, being the accuracy higher for compatible (error mean $M=3.99$ ) than for incompatible trials (error mean $\mathrm{M}=9.65$ ). No significant effect was observed for the acoustic stimulus modality $F(1,24)=3.37$, $M S E=37, p=0.08)$. No significant interactions were found.

Analyses of the incorrect responses at $\mathrm{T}-\mathrm{D}=1.30^{\circ}$ showed

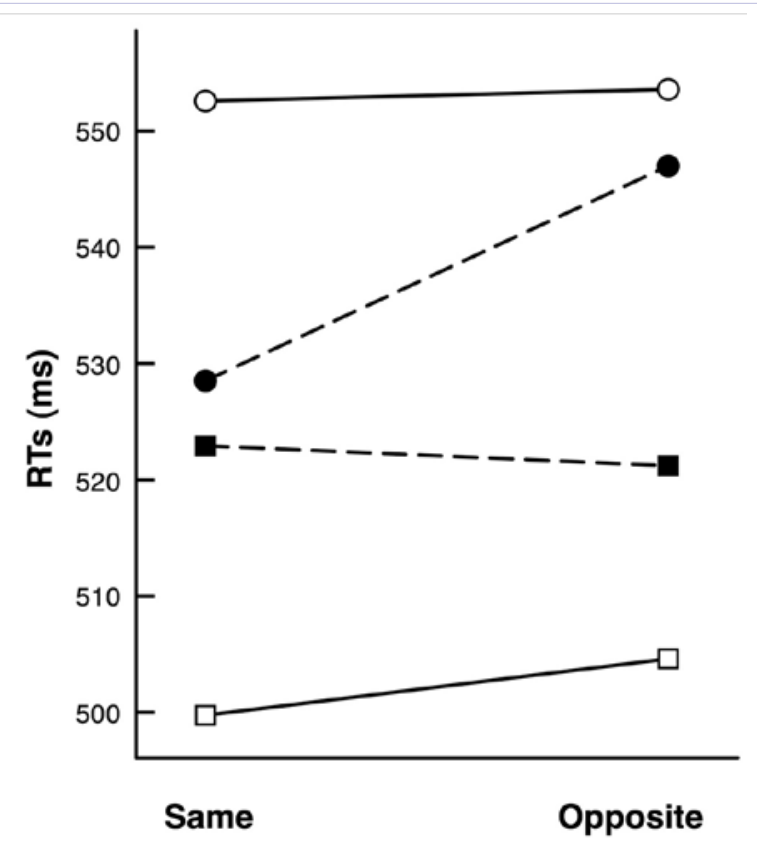

Figure 4: RT means as a function of the acoustic-stimulus congruency (same side or opposite side than the response) and compatibility ( incompatible compatible). Results from experiment 3 at $0.65^{\circ}$ (open symbols and solid lines) and $1.30^{\circ} \mathrm{T}$-D (filled symbols and dashed lines) distances. main effects of the compatibility of the current trial $\mathrm{F}(1,24)=$ 23.75, $\mathrm{MSE}=373, \mathrm{p}<0.001(\mathrm{M}=5.06$ for compatible and $\mathrm{M}=7.79$ for incompatible trials) and of the acoustic stimulus modality $\mathrm{F}(1,24)=5.84, \mathrm{MSE}=117, \mathrm{p}=0.024(\mathrm{M}=5.66$ for congruent and $\mathrm{M}=7.19$ for incongruent trials). No significant interactions were found.

\section{Discussion}

The experimental differences between the experiment 3 and the other two experiments avoid a direct comparison between the RTs and percentage of correct responses obtained, although an agreement with the results obtained in the two previous experiments is expected.

The first comparison that can be made is that the responses are also faster and more accurate for compatible than incompatible trials, decreasing the RCE with the T-D distance (51 $\mathrm{ms}$ and $16 \mathrm{~ms}$ for $0.65^{\circ}$ and $1.30^{\circ}$, respectively) as was previously obtained both in the absence and presence of acoustic stimuli. We have also obtained that the effect of the acoustic-stimuli congruency on the RTs and accuracy was no significant at the smaller T-D distance $\left(0.65^{\circ}\right)$. The existence of Simon effects is well documented from a long time ago [32,40,61 -67]. Activation models, translation models and dual-process models have been proposed to explain the mechanisms underlying Simon and flanker tasks (see for a review [67,68]). The expected Simon effect, however, took place significantly (RTs equal to 525 and $534 \mathrm{~ms}$ for congruent and incongruent acoustic stimuli) at the other T-D distance assayed $\left(1.30^{\circ}\right)$, such as happened in the experiment 2 for the same distance and display size. This Simon effect observed at the $1.30^{\circ}$ distance was only significant for the incompatible trials, (Figure 4). Consequently the RCE measured for incongruent acoustic stimuli (opposite side) was significantly larger than for congruent stimuli (same side), confirming our hypotheses on the existence of cross-modal interactions between visual and acoustic stimuli at low perceptual load and that the acoustic stimuli had a clear interference on the attentional focus. We think that results shown in Figure 4 clearly show an effect of the congruency of the acoustic stimuli on the visual cognitive control, measured by the RCE, i.e., by the exerting interference of visual distractors into the correct identification of target by the subjects. We were not able to detect this effect at shorter T-D distances or larger displays sizes. It appears to indicate the necessity of critical focus resolution or perceptual load to detect it represents a difficulty added to its study, which might explain why many authors did not find it, keeping on the actual controversy whether the attentional control is or not supramodal in nature. For this reason, we believe that the limitations to detect a crossmodal interaction on the cognitive control with either the focus or the perceptual load deserve a further study using a wider and more detailed range of the variables implied and additional tasks.

In summary we found: (i) Significant interference-flanker effects at all conditions studied, which increased with the T-D distances, in agreement with previous publications and predictions from the CTVA-2D model for the flanker task; (ii) 
Subjects carried out the visual task faster and more accurate in the presence than in the absence of the moderate sounds presented; (iii) A Simon effect was found a the larger T-D distance $\left(1.30^{\circ}\right)$, but not at the smaller distance $\left(0.65^{\circ}\right)$ assayed; and (iv) Stimuli from different sensorial modalities may affect the visual processing when the number of element displayed is small (three elements at the T-D distance of $1.30^{\circ}$ in our case), confirming our hypotheses on the existence of cross-modal interactions between visual and acoustic stimuli at low perceptual load.

\section{Acknowledgments}

This work was supported by the Spanish Ministerio de Educacion y Ciencia (Ref: SEJ2004- 05290). The authors gratefully acknowledge to Dr. John Trout for improving the English version.

\section{References}

1. Eriksen CW, St James JD (1986) Visual attention within and around the field of focal attention: a zoom lens model. Percept Psychophys 40(4): 225240 .

2. LaBerge D, Brown V (1989) Theory of attentional operations in shape identifications. Psychological Review 96(1): 101-124.

3. Cowan N, Elliott EM, Saults JS, Morey CC, Mattox S, et al. (2005) On the capacity of attention: its estimation and its role in working memory and cognitive aptitudes. Cogn Psychol 51(1): 42-100.

4. Lavie N (1995) Perceptual load as a necessary condition for selective attention. J Exp Psychol Hum Percep Perform 21(3): 451-468.

5. Lavie N (2005) Distracted and confused? selective attention under load Trends Cogn Sci 9(2): 75-82

6. Lavie N (2010) Attention, distraction, and cognitive control under load Current Directions in Psychological Science 19(3): 143-148

7. Lavie N, Tsal Y (1994) Perceptual load as a major determinant of the locus of selection in visual attention. Percept Psychophys 56(2): 183-197.

8. Lavie N, Hirst A, Fockert JW, Viding E (2004) Load theory of selective attention and cognitive control. J Exp Psychol Gen 133(3): 339-354.

9. Beri S, Schroger E (2003) Working memory controls involuntary attention switching: evidence from an auditory distraction paradigm. Eur J Neurosci 17(5): 1119-1122.

10. Burnham BR, Sabia M, Langan C (2014)Components of working memory and visual selective attention. J Exp Psychol Hum Percep Perform 40(1): 391-403.

11. Elliott EM, Barrilleaux KM, Cowan N (2006) Individual differences in the ability to avoid distracting sounds. European Journal of Cognitive Psychology 18(1): 90-108.

12. Hester R, Garavan H (2005) Working memory and executive function the influence of content and load on the control of attention. Memory Cognition 33(2): 221-233.

13. Kane MJ, Engle RW (2002) The role of prefrontal cortex in workingmemory capacity, executive attention, and general fluid intelligence: An individual-differences perspective. Psychon Bull Rev 9(4): 637-671.

14. Berman RA, Colby CL (2002) Auditory and visual attention modulate motion processing in area MT+. Cognitive Brain Research 14(1): 64-74.

15. Driver J, Spence C (1998) Crossmodal links in spatial attention. Philos Trans R Soc Lond Ser B, Biol Sci 353(1373): 1319-1331.

16. Duncan J, Martens S, Ward R (1997) Restricted attentional capacity within but not between sensory modalities. Nature 387(6635): 808-810.

17. Elliott EM, Cowan N, Valle-Inclan F (1998) The nature of cross-modal color-word interference effects. Percept Psychophys 60(5): 761-767.

18. Houghton R J, Macken WJ, Jones DM (2003) Attentional modulation of the visual motion aftereffect has a central cognitive locus: Evidence of interference by the postcategorical on the precategorical. J ExpPsychol Hum Percept Perform 29(4): 731-740.

19. Jolicoeur P (1999) Restricted attentional capacity between sensory modalities. Psychon Bull Rev 6(1): 87-92.

20. Morey CC, Cowan N (2005) When do visual and verbal memories conflict? The importance of working-memory load and retrieval. J Exp Psychol Learn Mem Cogn 31(4): 703-713.

21. Rees G, Frith CD, Lavie N (1997) Modulating irrelevant motion perception by varying attentional load in an unrelated task. Science 278(5343): 16161619.

22. Rees G, Frith CD, Lavie N (2001) Processing of irrelevant visual motion during performance of an auditory task. Neuropsychologia 39(9): 937-949.

23. Talsma D, Doty TJ, Strowd RE, Woldorff MG (2006) Attentional capacity for processing concurrent stimuli is larger across sensory modalities than within a modality. Psychophysiology, 43(6): 541-549.

24. Tombu M, Jolicoeur P (2003) A central capacity sharing model of dualtask performance. J Exp Psychol Hum Percept Perform 29(1): 3-18.

25. Eriksen BA, Eriksen CW (1974) Effects of noise letters upon the identification of a target letter in a nonsearch task. Perception Psychophysics 16(1): 143-149.

26. Alvarado JM, Santalla Z, Santisteban C (1998) Efecto de la segregacion sobre el procesamiento de la estimulacion visual. Psicologica 19(2): 87105.

27. Alvarado JM, Santalla Z, Santisteban C (1999) An evaluation of the CODE Theory of Visual Attention extended to two dimensions. Acta Psychologica 103(1-2): 239-255.

28. Eriksen CW (1995) The flanker task and response competition: a useful tool for investigating a variety of cognitive problems. In C. Bundesen $\mathrm{H}$. Shibuya (Eds.) Visual Selective Attention Hillsdale, USA, pp. 101-118.

29. Yantis S, Johnston JC (1990) On the locus of visual selection: Evidence from focused attention tasks. J Exp Psychol Hum Percept Perform 16(1): 135-149.

30. Logan GD (1996) The code theory of visual attention: an integration of space-based and object-based attention. Psychol Rev 103(4): 603-649.

31. Santisteban C, Alvarado JM, Cortijo M (2005) Evaluation of the perceptual grouping parameter in the CTVA model. Psicologica 26(2): 305-315.

32. Simon JR (1990) The effects of an irrelevant directional cue on human information processing. In R.W. Proctor TG. Reeve (Eds.), Stimulusresponse compatibility, North-Holland, New York, pp. 31-86.

33. Simon JR, Craft J (1970) Effects of an irrelevant auditory stimulus on visual choice reaction time. J ExpPsychol 86(2): 272-274.

34. Buchtel HA, Butter CM, (1988) Spatial attentional shifts: implications for the role of polysensory mechanisms. Neuropsychologia 26(4): 499-509.

35. Posner MI (1978) Chronometric explorations of mind. Lawrence Erlbaum Associates, Hillsdale, New Jersey.

36. Spence CJ, Driver J (1994) Covert spatial orienting in audition: exogenous and endogeno mechanisms. J Exp Psychol Hum Percept Perform 20(3): 555-574. 
37. Spence C, Driver J (1997) Audiovisual links in exogenous covert spatial orienting. Percept Psychophys 59(1): 1-22.

38. Spence C, McDonald J, Driver J (2004) Exogenous spatial cuing studies of human crossmodal attention and multisensory integration. In C. Spence J. Driver (Eds.), Crossmodal space and crossmodal attention Oxford, Oxford University Press, UK, pp. 277-320.

39. Alvarado JM, Santisteban C (2000) DEVAT: Design of experiments for visual attention tasks. Methods of Psychological Research (on-line) 5(4): $1-12$.

40. Alvarado JM, Santisteban C (2004) Compatibilidad de respuesta y el efecto Simon. Psicothema, 16(2): 276-281.

41. Santalla Z, Alvarado JM, Santisteban C(1999) ¿El ruido afecta a la focalización de la atención? Psicothema, 11(1): 97-111.

42. Daee S, Wilding JM (1977) Effects of high intensity white noise on shortterm memory for position in a list and sequence. Br J Psychol 68(3): 335349.

43. Davies DR, Jones DM (1975) The effects of noise and incentives upon attention in short-term memory. Br J Psychol 66(1): 61-68.

44. Hockey GRJ (1970a) Effects of locus noise on attentional selectivity. Quartely Journal of Experimental Psychology 22: 28-36.

45. Hockey R (1970b) Signals probability and spatial location as possible bases for increased selectivity in noise. Quartely Journal of Experimental Psychology 22(1): 37-42.

46. Hockey R, Hamilton P (1970) Arousal and information selection in shortterm memory. Nature, 226: 866-867.

47. Smith AP (1982) The effects of noise and task priority on recall of order and location. Acta Psychologica, 51: 245(3)-255.

48. Warner HD, Heimstra NW (1973) Target-detection performance as a function of noise intensity and task difficulty. Percept Mot Skills 36(2): 439-442.

49. Jones DM, Smith AP, Broadbent DE (1979) Effects of moderate intensity noise on the Balkan vigilance task. Journal of Applied Psychology 64: 627-634.

50. Smith AP (1985) The effects of noise on the processing of global shape and local detail. Psychological Research 47(2): 103-108.

51. Hartley LR, Adams RG (1974) Effects of noise on stroop test. Journal of Experimental Psychology 102(1): 62-66.

52. Houston B K, Jones TM (1967) Distraction and stroop colour-word performance. Journal of Experimental Psychology 74(1): 54-56.

53. O'Malley JJ, Poplaswky A (1971) Noise induced arousal and breath attention. Perceptual and Motor Skills 33(3): 887-890.

54. Usai MC, Umiltá C (1994) Effetti del rumore sul controllo del fuoco dell'attenzione. Giornale Italiano di Psicologia 21: 221-241.

55. Santisteban C, Santalla Z (1990) Efectos del ruido sobre memoria y atención: una revisión. Psicothema 2(2): 49-91.

56. Cowan N (2001) The magical number 4 in short-term memory: a reconsideration of mental storage capacity. Behav Brain Sci 24(1): 87-114.

57. Perez Edgar K, Fox NA (2003) Individual differences in children's performance during an emotional stroop task: a behavioral and electrophysiological study. Brain Cogn 52(1): 33-51.

58. Thomas SJ, Johnstone SJ, Gonsalvez CJ (2007) Event-related potentials during an emotional Stroop task. Int J Psychophysiol 63(3): 221-231.

59. Van Hooff JC, Dietz KC, Sharma D, Bowman H (2008) Neural correlates of intrusion of emotion words in a modified Stroop task. Int J Psychophysiol 67(1): 23-34.

60. Weissman DH, Gopalakrishnan A, Hazlett CJ Woldorff MG (2005) Dorsal anterior cingulate cortex resolves conflict from distracting stimuli by boosting attention toward relevant events. Cereb Cortex 15(2): 229-237.

61. De Jong R, Liang CC, Lauber E (1994). Conditional and unconditional automaticity: A dual-process model of effects of spatial stimulus-response correspondence. J Exp Psychol Hum Percept Perform 20(4): 731-750.

62. Gratton G, Coles MG, Sirevaag EJ, Eriksen CW, Donchin E (1988) Preand post-stimulus activation of response channels: a psychophysiological analysis. J Exp Psychol Hum Percept Perform14(3): 331-344.

63. Ivanoff J (2003) On spatial response code activation in a simon task. Acta Psychol 112(2): 157-179. Müsseler J, Koch I, Wühr P (2005) Testing the boundary conditions for processing irrelevant location information: the cross-task Simon effect. European Journal of Cognitive Psychology 17: 708-726.

64. Valle-Inclan F (1996) The locus of interference in the simon effect: an ERP study. Biological Psychology 43(2): 147-162.

65. Valle-Inclan F, Rumbo T, Redondo M, Lamas J (1995) El efecto Simon estudiado con potenciales cerebrales relacionados con el movimiento. Psicothema 7(1): 139-146.

66. Vallesi A, Mapelli D, Schiff S, Amodio P, Umilta C (2005) Horizontal and vertical Simon effect: different underlying mechanisms? Cognitionv 96(1): B33-B43.

67. Hasbroucq T, Burle B, Akamatsu M, Vidal F, Possamaï CA (2001) An electromyographic investigation of the effect of stimulus-response mapping on choice reaction time. Psychophysiology 38(1): 157-162. 